\title{
Is Palatal Rugae Morphology Stable in Patients Treated with Myofunctional Therapy in Skeletal Class II Cases?
}

\author{
Monika M. Ahuja ${ }^{1}$, Ranjit H. Kamble ${ }^{2}$, Sunita Shrivastava ${ }^{3}$, Navjeet S. Gurudatta ${ }^{4}$, \\ Pooja S. Bidwai ${ }^{5}$, Karthika M. Nambiar ${ }^{6}$ \\ 1, 2, 3, 4, 5, 6 Department of Orthodontics and Dentofacial Orthopaedics, Sharad \\ Pawar Dental College and Hospital, Sawangi, Maharashtra, India.
}

\section{ABSTRACT}

\section{BACKGROUND}

Palatine rugae are small transverse structures present in the anterior $2 / 3^{\text {rd }}$ of the palate. These rugae are protected by various structures of the oral cavity. They are immovable structures but variations in the oral cavity may lead to alterations in these small structures. There have been many studies that have quoted changes in these rugae patterns with various tooth movements whereas various other studies demonstrate no significant changes. None of the studies in specific have mentioned about palatal rugae changes with myofunctional appliances. The objective of this research was to evaluate the palatal rugae morphology and its stability after myofunctional therapy, as expansion and movement of teeth might lead to changes in these rugae.

\section{METHODS}

A total of 90 maxillary casts, 30 of Class I, 30 of Class II pre-treatment and casts of same subjects after myofunctional therapy, patients age ranging between 10 and 13 years were selected for the study. Length, intermedial and interlateral distances, angle of divergence and position of rugae were studied based on Lysell Classification 1955 and Thomas and Kotze Classification 1983.

\section{RESULTS}

Secondary and fragmentary rugae were found to be statistically significant as they were increased in Class II samples compared to Class I. The rugae in Class II samples were found to be shorter and therefore significant results were seen. IM1, IM2, IM4, IM5 and IM6 were found to be statistically significant respectively. Similarly, IL2, IL4, IL5 and IL6 were appreciable. IM1 was found to be appreciable. IL1, IL2, IL3 and IL4 were statistically significant. Significant difference was found in mean rugae value among Class I and Class II pre-treatment groups. Statistically significant difference was found in mean rugae value among Class I and Class II pre-treatment group. Incisive papilla to posterior border of last rugae (IP-PBA) was found to be statistically significant.

\section{CONCLUSIONS}

Myofunctional therapy did have an effect on the rugae pattern. But the age group of 10 - 13 years consisted of growing individuals. Therefore, it could not be concluded as to whether the changes were because of growth taking place or because of myofunctional therapy.

\section{KEY WORDS}

Palatine Rugae, Myofunctional Appliances, Class II Malocclusion
Corresponding Author: Dr. Monika Mohan Ahuja, Department of Orthodontics and Dentofacial Orthopaedics, Sharad Pawar Dental College and Hospital, Sawangi, Maharashtra, India. E-mail: dr.monikahuja303@gmail.com

DOI: $10.14260 / \mathrm{jemds} / 2021 / 122$

How to Cite This Article: Ahuja MM, Kamble RH, Shrivastava S, et al. Is palatal rugae morphology stable in patients treated with myofunctional therapy in skeletal Class II cases? J Evolution Med Dent Sci 2021;10(09):562566, DOI: 10.14260/jemds/2021/122

Submission 04-08-2020,

Peer Review 15-11-2020,

Acceptance 21-11-2020,

Published 01-03-2021.

Copyright (C) 2021 Monika M. Ahuja et al. This is an open access article distributed under Creative Commons Attribution License [Attribution 4.0 International (CC BY 4.0)] 


\section{BACKGROUND}

Palatine rugae or transverse palatine folds are haphazardly arranged raised projections of the mucosa, which are present in the preliminary part of the palate. These are the lateral membrane derivatives of the incisive papilla. The orientation of these rugae are in transverse direction from palatal raphe. These rugae are situated in the mid-sagittal plane. This was first described by Winslow. ${ }^{1}$

The first appearance of palatal rugae is by the $12^{\text {th }}$ week of intra uterine life. The connective tissue covering in the maxilla gives rise to these rugae. ${ }^{2}$

Palatal rugae are fibers which run in an anteroposterior direction within the core and athwart the base of each rugae they run in concentric curves, both of which determine and guide the forms of the palatal rugae. The connective tissue restricted beneath the regions of epithelial differentiation and thickening shows concentration of fibroblasts and collagen fibers, which explains varied shapes of rugae. ${ }^{3}$

Palatal rugae are relatively prominent in human embryos occupying a considerable amount of the length of the palatal vault during the period of their nascency. ${ }^{3}$

These rugae are well protected by structures present in the oral cavity i.e. teeth, lips, cheeks, tongue, bone and buccal pad of fat. All of these structures protect them from conditions like extreme temperature and trauma. ${ }^{4}$

Palatal rugae are immovable landmarks; although conditions like parafunctional habits such as thumb sucking, injury or trauma and / or orthodontic treatments bring about alterations in their patterns. ${ }^{5}$ During orthodontic treatment procedures, palatal rugae are considered as landmarks that indicate the amount of tooth migration. 6

Mills in 1991 stated that a functional appliance is "A removable or fixed appliance which changes the position of mandible due to forces generated by the stretching of the muscles, fascia and / or periosteum, through the appliance to the dentition and the underlying skeletal structures". They can be either tooth borne, or tooth and tissue borne. ${ }^{7}$ In the growing individual, interception of skeletal Class II malocclusion by alteration in growth direction is the best treatment option for mandibular retrognathism, which can be achieved by myofunctional appliances. ${ }^{8}$ Many of these appliances cover the palate and many have some influence over the pattern and morphology of the rugae.

Palatal rugae are considered as oral structures unique in their features, pertaining to an individual, like fingerprints which remain unchanged throughout his or her life. ${ }^{9}$ In the last few years the topic of palatine rugae has gained interest specially of the orthodontists as these have been found to be stable points, but in the literature review it is seen that orthodontic treatment may or may not lead to the modification in the rugae pattern and stability.

According to Van der Linden not much modification is seen in the length of anterior rugae after the age of $10 .{ }^{10}$ But there were other investigators who contradicted this and showed that with the advancement of age, the length of rugae changes. ${ }^{11}$ Certain extrinsic causes such as trauma, digit sucking, dentures, extractions of teeth and orthodontic interventions have altered the number and patterns of rugae. ${ }^{12}$

The qualitative and quantitative changes in the stability of the rugae, has to be recognised as related to any growth modification or application of force on the palate as seen in orthodontic tooth movement irrespective of its magnitude. ${ }^{13}$

Pavy and Kendrick found that the rugae pattern were specific for a specific case and tooth movement influenced the lateral ends of the rugae. ${ }^{14}$

Many studies have been reported on the varied patterns and location of palatal rugae once the orthodontic treatment was done but there is lack of data on the variations in structure and pattern in rugae with growth modulation therapy using appliances having palatal coverage. Thus, this research was conducted to estimate the rugae pattern and position in cases treated with myofunctional therapy and also to estimate the stability of the rugae to be used as a reference landmark for assessment of treatment outcome and growth changes.

\section{METHODS}

This cross-sectional study was conducted in the Department of Orthodontics and Dentofacial Orthopaedics at Sharad Pawar Dental College and Hospital.

30 Class I and 30 Class II division I cases according to Angle's classification prior to the treatment and same Class II div 1 case post myofunctional therapy were selected for the study. A total of 90 casts of children in active growth period

(Cervical Vertebrae Maturation Indicators-CVMI stage 2), age ranging from 10 to 13 years of age were selected. Study model impressions were taken of each sample. Impressions were poured in dental stone (Type II / IV) and bases were formed in dental plaster according to the standardised norms. Palatal rugae present on each study model impressions were coloured with thin tip marker under appropriate light and with the help of magnifying glass. The following parameters length, intermedial and interlateral distances, rugae pattern dimensions, angle of divergence was studied in two groups 1) Class I pre-treatment compared with Class II pre-treatment 2) Class II pre-treatment compared with Class II post treatment.

\section{Classification of Palatine Rugae (Lysell's Classification in 1955) ${ }^{15}$}

a. According to length - In this parameter the rugae length were ascertained with a digital caliper $(0.01 \mathrm{~mm})$ and then according to their length they were classified into three kinds as -

1. Primary category in which the length was more than $5 \mathrm{~mm}$.

2. Secondary category in which the length was between 3 - $5 \mathrm{~mm}$.

3. Fragmentary category in which the length was between $2-3 \mathrm{~mm}$.

b. The intermedial and interlateral distance of each rugae was measured by considering the medial and lateral points and measuring the distance between them with the help of vernier caliper $(0.01 \mathrm{~mm})$. Classification by Thomas and Kotze (1983) 16

c. Angle of divergence - This parameter was studied with the help of Auto Cad software in which the standardised photos that were taken were uploaded and measurements were done. 
To standardise the photographs, the distance from the maxillary base to the incisor was kept $40 \mathrm{~mm}$ for all casts. The distance of the camera to the incisor position was maintained at $39 \mathrm{cms}$.

Sony Alpha 580 camera, Lens-Tamron 90 mm F 2.8 macro lens (Sony mount) was used. Photo details - $1 / 200$ shutter speed, aperture F5, Iso 100 .

These standardised photographs were uploaded on Auto Cad software 2016 version and angles were measured with the help of the software.

Angle of divergence was ascertained on both the sides by the mid palatine raphe that was drawn and the line that joined the incisive papilla with the orientation of the last rugae present. Fragmentary rugae were not considered.

Origin of the rugae is the point near the palatal raphe whereas termination is the point away from the mid palatal raphe.

\section{Rugae Pattern Dimensions}

The rugae pattern dimensions were also studied on standardised photographs using Auto Cad software.

1. Incisive papilla to most anterior point (IP-AP) - Under this category the most anterior point of primary or secondary rugae whether on left or right were considered, and a line was drawn from this rugae to mid palatine raphe. The distance between the incisive papilla and the line joining the mid palatine raphe were then measured.

2. Incisive papilla to posterior border of last primary or secondary rugae (IP-PB3) - The most posterior point of primary or secondary rugae whether on left or right were considered, and a line was drawn from this rugae to mid palatine raphe. The distance between the incisive papilla and the line joining the mid palatine raphe were then measured.

3. Incisive papilla to posterior border of last rugae (IP-PBA) - The fragmentary rugae were considered and the distance from incisive papilla to last rugae were measured.

\section{Statistical Analysis}

Statistical analysis was done by using SPSS 14.0 version and Graph Pad Prism 7.0 version. Descriptive statistical analysis for all the variables was done to calculate the mean and standard deviation. Inferential statistical analysis was carried out using chi-square test, paired and unpaired t test. P-value less than $0.05(\mathrm{p}<0.05)$ was considered as level of significance.

\section{RESULTS}

The length of rugae in Class I and Class II pre-treatment is illustrated in Table 1. Secondary and fragmentary rugae were found to be statistically significant as they were increased in Class II samples compared to Class I $(\mathrm{P}=0.0001)$. The length of rugae in Class II pre- and post-treatment is demonstrated in Table 1 in which no much difference was found.

Comparison of intermedial and interlateral distance in Class I and Class II pre-treatment is described in Table 2. The rugae in Class II samples were found to be shorter and therefore significant results were seen. IM1, IM2, IM4, IM5 and IM6 were found to be statistically significant $(\mathrm{P}=0.0001),(\mathrm{P}=$ 0.022), $(\mathrm{P}=0.0001),(\mathrm{P}=0.011)$ and $(\mathrm{P}=0.042)$ respectively. Similarly, IL2, IL4, IL5 and IL6 were appreciable. ( $\mathrm{P}=0.0001)$, $(\mathrm{P}=0.0001),(\mathrm{P}=0.011)$ and $(\mathrm{P}=0.042)$ respectively. Comparison of intermedial and interlateral distance in Class II pre- and post-treatment is illustrated in Table 3. IM1 was found to be appreciable ( $\mathrm{P}=0.008)$. IL1, IL2, IL3 and IL4 were statistically significant $(\mathrm{P}=0.0001),(\mathrm{P}=0.0001)$ and $(\mathrm{P}=$ $0.0001)$ and $(P=0.003)$ respectively.

\begin{tabular}{|c|c|c|c|c|c|}
\hline & \multicolumn{2}{|c|}{ Class I } & \multicolumn{2}{|c|}{ Class II } & \multirow[t]{2}{*}{ «2-Value } \\
\hline & Present & Absent & Present & Absent & \\
\hline Primary & $\begin{array}{c}30 \\
(100 \%)\end{array}$ & $\begin{array}{c}0 \\
(0 \%)\end{array}$ & $\begin{array}{c}30 \\
(100 \%)\end{array}$ & $\begin{array}{c}0 \\
(0 \%)\end{array}$ & - \\
\hline $\begin{array}{c}\text { Seconda } \\
\text { ry }\end{array}$ & $\begin{array}{c}2 \\
(6.67 \%)\end{array}$ & $\begin{array}{c}28 \\
(93.33 \\
\%)\end{array}$ & $\begin{array}{c}27 \\
(90 \%)\end{array}$ & $\begin{array}{c}3 \\
(10 \%)\end{array}$ & $\begin{array}{l}41.28, \mathrm{P}= \\
0.0001, \mathrm{~S}\end{array}$ \\
\hline \multirow[t]{3}{*}{$\begin{array}{l}\text { Frag- } \\
\text { mentary }\end{array}$} & $\begin{array}{c}0 \\
(0 \%)\end{array}$ & $\begin{array}{c}30 \\
(100 \%)\end{array}$ & $\begin{array}{c}19 \\
(63.33 \%)\end{array}$ & $\begin{array}{c}11(36.67 \\
\%)\end{array}$ & $\begin{array}{c}27.80, P= \\
0.0001, S\end{array}$ \\
\hline & \multicolumn{2}{|c|}{ Pre-Treatment } & \multicolumn{2}{|c|}{ Post Treatment } & $\aleph 2$-Value \\
\hline & Present & Absent & Present & Absent & \\
\hline Primary & $\begin{array}{c}30(100 \\
\%)\end{array}$ & $\begin{array}{c}0 \\
(0 \%)\end{array}$ & $\begin{array}{c}30 \\
(100 \%)\end{array}$ & $\begin{array}{c}0 \\
(0 \%)\end{array}$ & \\
\hline $\begin{array}{l}\text { Secon- } \\
\text { dary }\end{array}$ & $\begin{array}{c}27 \\
(90 \%)\end{array}$ & $\begin{array}{c}3 \\
(10 \%)\end{array}$ & $\begin{array}{c}25 \\
(83.33 \%)\end{array}$ & $\begin{array}{c}5 \\
(16.67 \%)\end{array}$ & $\begin{array}{c}0.57 \\
P= \\
0.44, \mathrm{NS}\end{array}$ \\
\hline $\begin{array}{c}\text { Frag- } \\
\text { mentary }\end{array}$ & $\begin{array}{c}19 \\
(63.33 \%)\end{array}$ & $\begin{array}{c}11 \\
(36.67 \\
\%)\end{array}$ & $\begin{array}{c}14 \\
(46.67 \%)\end{array}$ & $\begin{array}{c}16 \\
(53.33 \%)\end{array}$ & $\begin{array}{c}1.68, \\
P= \\
0.19, \mathrm{NS}\end{array}$ \\
\hline
\end{tabular}

Table 1. Comparison of Length of Rugae in Class I, Class II, Pre-Treatment and Post Treatment

\begin{tabular}{|c|c|c|c|c|c|c|c|}
\hline \multirow{2}{*}{ Distance } & \multicolumn{2}{|c|}{ Class I } & \multicolumn{2}{|c|}{ Class II } & \multirow{2}{*}{$\begin{array}{c}\text { Mean } \\
\text { Difference }\end{array}$} & \multirow{2}{*}{$\begin{array}{c}\text { t- } \\
\text { Value }\end{array}$} & \multirow{2}{*}{ P-Value } \\
\hline & Mean & SD & Mean & SD & & & \\
\hline IM1 & 1.78 & 0.55 & 2.88 & 0.85 & $1.10 \pm 0.18$ & 6.000 & $0.0001, \mathrm{~S}$ \\
\hline IM2 & 6.94 & 2.60 & 5.50 & 2.07 & $1.43 \pm 0.60$ & 2.363 & $0.022, \mathrm{~S}$ \\
\hline IM3 & 6.21 & 5.64 & 6.47 & 3.08 & $0.26 \pm 1.17$ & 0.226 & 0.822 ,NS \\
\hline IM4 & 0.00 & 0.00 & 4.76 & 5.33 & $4.58 \pm 0.98$ & 4.627 & $0.0001, \mathrm{~S}$ \\
\hline IM5 & 0.00 & 0.00 & 3.21 & 6.74 & $3.21 \pm 1.23$ & 2.610 & $0.011, \mathrm{~S}$ \\
\hline IM6 & 0.00 & 0.00 & 1.29 & 3.39 & $1.28 \pm 0.61$ & 2.100 & $0.042, \mathrm{~S}$ \\
\hline IL1 & 14.91 & 4.96 & 12.42 & 5.51 & $2.48 \pm 1.35$ & 1.834 & $0.072, \mathrm{NS}$ \\
\hline IL2 & 19.30 & 4.31 & 14.30 & 5.01 & $4.99 \pm 1.20$ & 4.143 & $0.0001, S$ \\
\hline IL3 & 14.65 & 10.36 & 14.43 & 3.83 & $0.21 \pm 2.01$ & 0.107 & $0.915, \mathrm{NS}$ \\
\hline IL4 & 0.00 & 0.00 & 8.72 & 9.13 & $8.71 \pm 1.66$ & 5.228 & $0.0001, S$ \\
\hline IL5 & 0.00 & 0.00 & 3.54 & 7.40 & $3.53 \pm 1.35$ & 2.616 & $0.011, \mathrm{~S}$ \\
\hline IL6 & 0.00 & 0.00 & 1.84 & 4.85 & $1.83 \pm 0.87$ & 2.100 & $0.042, \mathrm{~S}$ \\
\hline
\end{tabular}

\begin{tabular}{|c|c|c|c|c|c|c|c|}
\hline \multirow[t]{2}{*}{ Distance } & \multicolumn{2}{|c|}{$\begin{array}{c}\text { Pre- } \\
\text { Treatment }\end{array}$} & \multicolumn{2}{|c|}{$\begin{array}{c}\text { Post- } \\
\text { Treatment }\end{array}$} & \multirow[t]{2}{*}{$\begin{array}{c}\text { Mean } \\
\text { Difference }\end{array}$} & \multirow[t]{2}{*}{$\begin{array}{c}\text { t - } \\
\text { Value }\end{array}$} & \multirow[t]{2}{*}{ P-Value } \\
\hline & Mean & SD & Mean & SD & & & \\
\hline IM1 & 2.88 & 0.85 & 3.30 & 1.05 & $0.41 \pm 0.79$ & 2.829 & $0.008, \mathrm{~S}$ \\
\hline IM2 & 5.50 & 2.07 & 5.94 & 2.11 & $0.43 \pm 1.43$ & 1.671 & 0.105 ,NS \\
\hline IM3 & 6.47 & 3.08 & 6.82 & 2.63 & $0.34 \pm 1.48$ & 1.277 & 0.212 ,NS \\
\hline IM4 & 4.76 & 5.33 & 4.77 & 5.15 & $0.00 \pm 1.17$ & 0.003 & $0.998, \mathrm{NS}$ \\
\hline IM5 & 3.21 & 6.74 & 3.65 & 7.11 & $0.43 \pm 1.51$ & 1.570 & $0.127, \mathrm{NS}$ \\
\hline IM6 & 1.29 & 3.39 & 2.67 & 5.95 & $1.38 \pm 5.16$ & 1.040 & 0.316 ,NS \\
\hline IL1 & 12.42 & 5.51 & 13.10 & 5.65 & $0.68 \pm 0.69$ & 5.352 & $0.0001, \mathrm{~S}$ \\
\hline IL2 & 14.30 & 5.01 & 15.27 & 5.41 & $0.96 \pm 1.13$ & 4.654 & $0.0001, \mathrm{~S}$ \\
\hline IL3 & 14.43 & 3.83 & 15.29 & 4.11 & $0.85 \pm 1.13$ & 4.129 & $0.0001, \mathrm{~S}$ \\
\hline IL4 & 8.72 & 9.13 & 9.18 & 9.60 & $0.45 \pm 0.77$ & 3.211 & $0.003, S$ \\
\hline IL5 & 3.54 & 7.40 & 3.61 & 7.55 & $0.07 \pm 0.24$ & 1.608 & $0.119, \mathrm{NS}$ \\
\hline IL6 & 1.84 & 4.85 & 1.85 & 4.87 & $0.006 \pm 0.05$ & 0.435 & $0.670, \mathrm{NS}$ \\
\hline & $\begin{array}{r}\text { 3. Com } \\
\text { in } \mathrm{Cl}\end{array}$ & 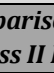 & f Int & r & and Interla & eral D & tance \\
\hline
\end{tabular}

Comparison of angle of divergence in Class 1 and Class II pretreatment is given in Table 4. Significant difference was found in mean rugae value among Class I and Class II pre-treatment group with $(\mathrm{P}=0.0001)$ and $(\mathrm{P}=0.015)$ respectively. Comparison of angle of divergence in Class II pre- and posttreatment is illustrated in Table 7. Statistically significant 
difference was found in mean rugae value among Class I and Class II pre-treatment group. $(\mathrm{P}=0.0001)$ and $(\mathrm{P}=0.015)$ respectively.

Comparison of rugae pattern dimensions in the Class I and Class II pre-treatment is illustrated in Table 6. IP-PBA was found to be statistically significant $(\mathrm{P}=0.0001)$. Comparison of rugae pattern dimensions in Class II pre- and posttreatment is demonstrated in Table 7 and noticeable difference was found.

\begin{tabular}{|cccccccc|}
\hline Angle of & \multicolumn{3}{c|}{ Class I } & \multicolumn{2}{c|}{ Class II } & \multicolumn{3}{c|}{ Mean } & \multirow{2}{*}{ t-Value } & \multirow{2}{*}{ P-Value } \\
Divergence & Mean & SD & Mean & SD & Difference & \\
\hline Right & 11.16 & 1.08 & 20.10 & 5.91 & $8.93 \pm 1.09$ & 8.13 & $0.0001, \mathrm{~S}$ \\
Left & 14.86 & 3.48 & 18.20 & 6.42 & $3.33 \pm 1.33$ & 2.49 & $0.015, \mathrm{~S}$ \\
\hline \multicolumn{8}{c}{ Table 4. Comparison of Angle of Divergence } \\
in Class I and Class II Pre-Treatment
\end{tabular}

\begin{tabular}{|c|c|c|c|c|c|c|c|}
\hline \multirow{2}{*}{$\begin{array}{c}\text { Angle of } \\
\text { Divergence }\end{array}$} & \multicolumn{2}{|c|}{$\begin{array}{c}\text { Pre- } \\
\text { Treatment }\end{array}$} & \multicolumn{2}{|c|}{$\begin{array}{c}\text { Post- } \\
\text { Treatment }\end{array}$} & \multirow{2}{*}{$\begin{array}{c}\text { Mean } \\
\text { Difference }\end{array}$} & \multirow{2}{*}{ t-Value } & \multirow[t]{2}{*}{ P-Value } \\
\hline & Mean & SD & Mean & SD & & & \\
\hline Right & 20.10 & 5.91 & 22.13 & 6.44 & $2.03 \pm 7.74$ & 1.43 & $0.16, \mathrm{NS}$ \\
\hline Left & 18.20 & 6.42 & 19.86 & 5.96 & $1.66 \pm 8.71$ & 1.04 & $0.30, \mathrm{NS}$ \\
\hline \multicolumn{8}{|c|}{$\begin{array}{l}\text { Table 5. Comparison of Angle of Divergence in } \\
\text { Class II Pre-Treatment and Post-Treatment }\end{array}$} \\
\hline
\end{tabular}

\begin{tabular}{|c|c|c|c|c|c|c|c|}
\hline \multirow{2}{*}{$\begin{array}{c}\text { Rugae } \\
\text { Pattern } \\
\text { Dimensions }\end{array}$} & \multicolumn{2}{|c|}{ Class I } & \multicolumn{2}{|c|}{ Class II } & \multirow{2}{*}{$\begin{array}{c}\text { Mean } \\
\text { Difference }\end{array}$} & \multirow{2}{*}{ t-Value } & \multirow[b]{2}{*}{ P-Value } \\
\hline & Mean & SD & Mean & SD & & & \\
\hline IP-AP & 7.31 & 0.57 & 6.97 & 0.72 & $0.34 \pm 0.16$ & 2.02 & $0.048, \mathrm{~S}$ \\
\hline IP-PB3 & 22.39 & 0.82 & 22.69 & 1.76 & $0.29 \pm 0.35$ & 0.83 & $0.40, \mathrm{NS}$ \\
\hline IP-PBA & 0 & 0 & 14.79 & 12.35 & $14.79 \pm 2.25$ & 6.55 & $0.0001, \mathrm{~S}$ \\
\hline \multicolumn{8}{|c|}{$\begin{array}{c}\text { Table 6. Comparison of Rugae Pattern Dimensions } \\
\text { in Class I and Class II Pre-Treatment }\end{array}$} \\
\hline
\end{tabular}

\begin{tabular}{|c|c|c|c|c|c|c|c|}
\hline \multirow{2}{*}{\begin{tabular}{|c|} 
Rugae \\
Pattern \\
Dimensions
\end{tabular}} & \multicolumn{2}{|c|}{$\begin{array}{c}\text { Pre- } \\
\text { Treatment }\end{array}$} & \multicolumn{2}{|c|}{$\begin{array}{c}\text { Post } \\
\text { Treatment }\end{array}$} & \multirow{2}{*}{$\begin{array}{c}\text { Mean } \\
\text { Difference }\end{array}$} & \multirow{2}{*}{ t-Value } & \multirow[t]{2}{*}{ P-Value } \\
\hline & Mean & SD & Mean & SD & & & \\
\hline IP-AP & 6.97 & 0.72 & 6.98 & 0.72 & $0.01 \pm 0.03$ & 1.80 & $0.08, \mathrm{NS}$ \\
\hline IP-PB3 & 22.69 & 1.76 & 22.76 & 1.78 & $0.06 \pm 0.22$ & 1.61 & $0.11, \mathrm{NS}$ \\
\hline IP-PBA & 15.30 & 12.25 & 14.36 & 12.35 & $0.93 \pm 5.03$ & 1.00 & $0.32, \mathrm{NS}$ \\
\hline \multicolumn{8}{|c|}{$\begin{array}{l}\text { Table 7. Comparison of Rugae Pattern Dimensions } \\
\text { in Class II Pre-Treatment and Post Treatment }\end{array}$} \\
\hline
\end{tabular}

\section{DISCUSSION}

The objective of this research is to evaluate the rugae pattern and position in cases which are treated with myofunctional therapy and also to estimate the stability of these rugae to be used as a reference landmark for determination of treatment outcome and with growth. Many myofunctional appliances that covers the palate have an effect on the palatal rugae to some extent.

On comparing the length of rugae in the Class I and the Class II pre-treatment it showed that the primary rugae were present in both the groups. Secondary and tertiary rugae were noticeably more in Class II sample and both secondary and tertiary rugae were found to be appreciably significant. (Table 1)

The palate of Class II patients is usually narrow and constricted, therefore we also see a constriction in the rugae of these samples.

Hauser et al (1989) ${ }^{17}$ mentioned that the development of the rugae were affected by the size of the palate. Our outcome showed results which was similar to a study done by Gandikota et al $(2012)^{6}$ in which they found a difference in the transverse width of first three rugae that were shorter in Class
II division 1 malocclusion samples. He mentioned that this result showed constriction in the arches of Class II division 1 malocclusion as compared to Class I individuals.

On comparing the length of rugae in Class II pre- and posttreatment, primary rugae were found in all subjects, secondary and tertiary rugae had reduced in number in post treatment however, statistically non-significant difference was found. (Table 1)

Secondary and tertiary rugae may have reduced in number in Class II because of the increase in length that might have occurred because of the palatal coverage or expansion done simultaneously with these appliances. Therefore, according to the criteria of the classification for length of the rugae and owing to the increase in length post treatment, secondary rugae might have converted into primary and tertiary to secondary thus, reducing the number of secondary and tertiary rugae.

A study conducted by Damstra et al (2009) ${ }^{18}$ on variations in palatal rugae antero-posteriorly and in transverse direction after rapid expansion of maxilla gave results dissimilar to our study and showed that transverse changes with the $3^{\text {rd }}$ rugae was more marked as compared to the $2^{\text {nd }}$ and $1^{\text {st }}$ rugae.

Pillai (2016) ${ }^{19}$ observed changes in the transverse plane in rugae pattern post palatal expansion between the medial ends of rugae. As and when the patient undergoes orthodontic intervention there is appreciable increment in the arch perimeter because of which it is most likely that there is a variation in shape, number and position of rugae.

On comparing the intermedial and interlateral distance in Class I and Class II pre-treatment group, the intermedial distance in Class II individuals was comparatively larger and significant difference was found except for the $3^{\text {rd }}$ rugae. The lateral distance was found to be more in Class I individuals except for $1^{\text {st }}$ and $3^{\text {rd }}$ rugae. The results were significant for all the rugae except IL1 and IL3. (Table 2)

The Class II subjects had constricted rugae and were placed away from the mid palatine raphe compared to Class I rugae. Therefore, there was significant changes in the medial points when compared. The $3^{\text {rd }}$ rugae were not affected and were non-significant in both the groups. Class I rugae being longer showed significant changes in the lateral points, as they were farther away in the palate compared to Class II. There was slight change in IL5 and IL6 and therefore, were not significant.

Comparing the intermedial and interlateral distance in Class II pre- and post-treatment. The intermedial distance was found to be non-significant except for the $1^{\text {st }}$ rugae which was significant and interlateral distance was found to be nonsignificant for $5^{\text {th }}$ and $6^{\text {th }}$ rugae but significant for all other rugae. (Table 3 )

Due to pressure exerted on the palate by myofunctional appliances having palatal coverage and also due to the expansion that might have taken place, there was a change in length of the rugae. The first rugae seemed to increase the maximum in the medial and lateral regions. Similarly, the $2^{\text {nd }}$, $3^{\text {rd }}$ and $4^{\text {th }}$ rugae seemed to increase in lateral direction to significant levels. These changes were seen because of the differential forces that might have acted on the palate at different areas due to the appliance.

Comparing the angle of divergence in the Class I and the Class II pre-treatment samples, the mean size of rugae in Class I samples was comparatively larger and the rugae were near to mid palatine raphe compared to Class II samples. Therefore, 
the mean angle was found to be more in Class I samples on right as well as left side and were statistically significant. (Table 4)

The angle of divergence when compared in Class II preand post-treatment groups the mean angle of rugae on right and left sides was statistically non-significant and not many changes were found in the angle on both sides. (Table 5)

As there were not many changes in the point that was near the midline of the last primary or secondary rugae post treatment, this angle did not show much change.

When the rugae pattern dimensions were compared in Class I and Class II pre-treatment groups, appreciable results were found for IP-AP and IP-PBA. IP-AP was more in Class I group which signifies that the $1^{\text {st }}$ rugae in Class I is distantly placed as compared to Class II. (Table 6) Class I samples did not have any fragmentary rugae whereas they were seen in Class II, therefore, IP-PBA was found significant.

On comparing rugae pattern dimensions in Class II preand post-treatment no noteworthy differences were found. (Table 7) This parameter was not studied in the literature before and therefore, we cannot compare our results with any other studies.

\section{CONCLUSIONS}

Myofunctional therapy did have an effect on the rugae. The length of the rugae was smaller in Class II which might be due to constricted palate in these patients. The intermedial and interlateral distances after myofunctional therapy had increased which might have been due to the pressure applied by these appliances and also due to expansion that might have occurred. Class I and Class II samples also showed variations in the angle of divergence and position of rugae by which we can conclude that different malocclusions have a specific pattern in which these rugae are oriented.

\section{Limitations}

The models that were taken after myofunctional therapy, were taken immediately after the therapy, so there may be a chance that these are temporary changes that were observed and the rugae pattern and position may relapse with time. The age group selected was growing age, therefore we cannot comment if the changes were because of growth or because of myofunctional therapy.

Data sharing statement provided by the authors is available with the full text of this article at jemds.com.

Financial or other competing interests: None.

Disclosure forms provided by the authors are available with the full text of this article at jemds.com.

\section{REFERENCES}

[1] Sivaraj A. Significance of palatal rugae in orthodontics. Journal of Orofacial Research 2013;3(3):202-9.
[2] Jain A, Chowdhary R. Palatal rugae and their role in forensic odontology. J Invest Clini Dent 2014;5(3):171-8.

[3] Rajan VP, John JB, Stalin A, et al. Morphology of palatal rugae patterns among 5-15 years old children. J Pharm Bioallied Sci 2013;5(Suppl 1):S43-7.

[4] Chandra S, Pandey V, Wasti A, et al. Analysis of rugae pattern in Ranchi and Patna population. Journal of International Oral Health 2016;8(3):362-6.

[5] Kapali S, Townsend G, Richards L, et al. Palatal rugae patterns in Australian Aborigines and Caucasians. Aust Dent J 1997;42(2):129-33.

[6] Gandikota C, Venkata YP, Challa P, et al. Comparative study of palatal rugae pattern in Class II div 1 and Class I individuals. J Pharm Bioallied Sciences 2012;4(Suppl 2):S358-63.

[7] Crawford EC. Dentofacial orthopedics with functional appliances [Book Review]. Australian Orthodontic Journal 1986;9(4):350.

[8] Sharma N, Shrivastav S, Kamble R, et al. A Tailored approach for growth modification: an innovative approach. World Journal of Dentistry 2017;8(4):334-42.

[9] van der Linden FP. Changes in the position of posterior teeth in relation to ruga points. Am J Orthod 1978;74(2):142-61.

[10] Simmons JD, Moore RN, Erickson LC. A longitudinal study of anteroposterior growth changes in the palatine rugae. J Dent Res 1987;66(9):1512-5.

[11] Peavy DC, Kendrick GS. The effects of tooth movement on the palatine rugae. J Prosthetic Dent 1967;18(6):536-42.

[12] Shukla D, Chowdhry A, Bablani D, et al. Establishing the reliability of palatal rugae pattern in individual identification (following orthodontic treatment). J Forensic Odontostomatol 2011;29(1):20-9.

[13] Kapoor P, Miglani R. Transverse changes in lateral and medial aspects of palatal rugae after mid palatal expansion: a pilot study. J Forensic Dent Sci 2015;7(1):813.

[14] Hoggan BR, Sadowsky C. The use of palatal rugae for the assessment of anteroposterior tooth movements. Am J Orthod Dentofacial Orthop 2001;119(5):482-8.

[15] Lysell L. Plicae palatinae transversae and papilla incisiva in man: a morphologic and genetic study. Acta Odontol Scand 1955;13(Suppl 18):5-137.

[16] Thomas CJ, Kotze TJ, Van der Merwe CA. An improved statistical method for the racial Classification of man by means of palatal rugae. Archives of Oral Biology 1987;32(4):315-7.

[17] Hauser G, Daponte A, Roberts MJ. Palatal rugae. J Anat 1989;165:237-49.

[18] Damstra J, Mistry D, Cruz C, et al. Antero-posterior and transverse changes in the positions of palatal rugae after rapid maxillary expansion. European Journal of Orthodontics 2009;31(3):327-32.

[19] Pillai J, Banker A, Bhattacharya A, et al. Quantitative and qualitative analysis of palatal rugae patterns in Gujarati population: a retrospective, cross-sectional study. J Forensic Dent Sci 2016;8(3):126. 